\title{
El Camino Real de Tierra Adentro y la colonización en la jurisdicción de las villas de San Miguel y San Felipe en EL SIGLO XVI
}

\author{
Miguel Santos Salinas Ramos*
}

\begin{abstract}
Resumen
El objetivo de este trabajo es mostrar la importancia del Camino Real de Tierra Adentro en el proceso de colonización en la jurisdicción de las villas de San Miguel y San Felipe en el siglo Xvı. Esta ruta histórica fue un referente geográfico para fundar ambas villas, así como para la donación de mercedes de tierra para estancias de ganado y labores agrícolas. Durante el periodo virreinal este camino fue la vía principal para entrar a tierras septentrionales, y siguió funcionando hasta la segunda mitad del siglo xIX, cuando inició su decadencia y abandono.
\end{abstract}

Palabras clave: Colonización, Camino Real, villa de San Miguel.

\begin{abstract}
The objective of this paper is to show the importance of the Camino Real de Tierra Adentro in the colonization process in the jurisdiction of the towns of San Miguel and San Felipe in the sixteenth century. This historic route was a geographic reference to found both towns, and for donating land grants for cattle farms and agriculture. During the colonial period this road was the main route to enter northern lands and continued to operate until the second half of the nineteenth century, when it began its decline and abandonment.
\end{abstract}

Key Words: Colonization, Camino Real, town of San Miguel.

\footnotetext{
* unAm, Escuela Nacional de Estudios Superiores, Unidad León.
} 


\section{Introducción}

Desde el siglo XVI y hasta las primeras décadas del siglo XIX, hubo en la Nueva España varios caminos que conectaban a la ciudad de México con los puertos y ciudades más importantes del virreinato. De la ciudad de México se iba a Veracruz y Acapulco, lugares desde donde se enviaban mercancías a Europa y Asia. Igualmente, por estos puertos entraban telas, marfil, porcelanas, joyas y especias; en general, eran lugares donde se comercializaban objetos y productos de diferentes continentes.

Además de estos puertos, había caminos que conectaban a las principales ciudades al interior de la Nueva España, siendo el más importante el Camino Real de Tierra Adentro, ruta que por más de tres siglos permitió la comunicación y comercio entre la ciudad de México y las principales poblaciones del septentrión novohispano.

\section{1.- El descubrimiento de Zacatecas}

Después de que los españoles derrotaron a los mexicas y pusieron bajo su control a las poblaciones del valle de México, extendieron su dominio hacia el occidente, hasta tomar posesión del imperio Tarasco; conquistado este amplio territorio, realizaron expediciones rumbo al norte y occidente del río Grande -actual río Lerma-, el cual, a la llegada de los españoles, era la frontera geográfica y cultural entre Mesoamérica y la región del norte, donde vivían grupos de tradición nómada, cazadores y recolectores comúnmente llamados chichimecas.

Estas expediciones tenían varios objetivos: encontrar una ruta hacia el Pacífico la cual comunicara a la Nueva España con el lejano oriente, descubrir nuevos territorios que formaran parte de la corona española y encontrar aquella ciudad mítica llena de tesoros conocida como Cíbola, cuyas riquezas compensarían los esfuerzos y peligros de las expediciones.

Este proceso de extensión del dominio español sobre los nuevos territorios, implicó la ocupación y apropiación del espacio que se iba descubriendo. Los españoles llegaron con la intención de establecerse y, para ello, fundaron pueblos y ciudades, siendo la más importante en el 
occidente la ciudad de Guadalajara; ${ }^{1}$ sin embargo, este proceso llevó consigo el desplazamiento de los chichimecas, quienes se resistieron a la invasión del territorio que por generaciones habían ocupado.

De este encuentro de culturas surgió el conflicto conocido como la guerra del Mixtón, (1541-1542) llamada así porque culminó con una batalla en el cerro del Mixtón, ${ }^{2}$ donde los chichimecas cazcanes ${ }^{3}$ que resistieron fueron derrotados.

Terminado este conflicto y controlada la región, no pacificada del todo, los españoles iniciaron expediciones hacia el norte en busca de riquezas que recompensaran sus esfuerzos en las campañas de conquista y pacificación. Una de estas expediciones dio resultado en septiembre de 1546, cuando un grupo comandado por Juan de Tolosa entró en tierras del norte y, después de entablar relación con un grupo de indios zacatecos -quienes le indicaron el lugar de donde habían obtenido algunas pepitas de plata-, descubrió los ricos yacimientos de Zacatecas. ${ }^{4}$

Este acontecimiento atrajo a exploradores, mineros, comerciantes, soldados y demás expedicionarios, quienes recorrían grandes distancias desde México, Guadalajara o Michoacán para participar en la explotación de las minas o abastecer a los pobladores que se iban asentando en los alrededores del lugar. El descubrimiento de Zacatecas hizo necesario construir caminos, establecer rutas y asegurar los trayectos para trasladar la plata a las ciudades de Guadalajara y México para su acuñación; además, eran indispensables los caminos para llevar insumos, alimentos y herramientas a la población.

1 Se fundó en 1531, sin embargo después de varios intentos por reubicarla, finalmente en el año de 1542 se estableció en su sitio actual. Bakewell, Minería y sociedad en el México colonial, p.18; Gerhard, La frontera norte de la Nueva España, pp. 118-119.

2 El cerro se ubica al oeste del valle de Juchipila, al sur del actual estado de Zacatecas. El primer virrey Antonio de Mendoza, quien gobernó de 1535 a 1550 participó personalmente en esta batalla. Powell, La Guerra Chichimeca, p. 20.

3 Los cazcanes fueron uno de los diversos grupos chichimecas que habitaron la región al norte del río Grande -actual Lerma-. Se extendían desde el norte del lago de Chapala hasta el sur del actual estado de Zacatecas. Otros grupos chichimecas eran los guamares, que se encontraban en la parte central del territorio que actualmente corresponde al estado de Guanajuato; los guachichiles, concentrados principalmente en el norte del estado de Guanajuato y en San Luis Potosí; y los zacatecos, en el territorio del actual estado de Zacatecas. Sobre las costumbres y territorios de ocupación de estos grupos, véanse las obras de Guillermo de Santa María, Guerra de los chichimecas, y Powell, La Guerra Chibimeca., en especial el capítulo III.

4 Powell, op. cit., p. 26-27. Román Gutiérrez, Sociedad y evangelización en Nueva Galicia en el siglo XVI, p. 56-57. 
El camino principal que comunicaba a las minas de Zacatecas con la ciudad de México fue el Camino de la Plata, ${ }^{5}$ aunque el término más apropiado es Camino Real de Tierra Adentro, porque durante el periodo virreinal y buena parte del siglo xix fue, más que la ruta de la plata, la vía principal para entrar a tierras septentrionales y llegar hasta Santa Fe, en Nuevo México. ${ }^{6}$ En un primer momento histórico sirvió para transportar el mineral, sin embargo, sus funciones fueron más allá al ser una ruta de colonización, evangelización, comercio y pacificación, ya que por ella circularon soldados, expedicionarios, pobladores, comerciantes, evangelizadores y ganaderos. ${ }^{7}$

Este camino, que se volvió más importante con el descubrimiento de las minas de Guanajuato en 1556, ${ }^{8}$ atravesaba la región al norte del río Grande, siendo sus principales estaciones Cuautitlán, Tepeji, Jilotepec y San Juan del Río, seguía hacia Querétaro, donde se dividía en dos trayectos: uno dirigido a San Miguel, que tomaba el curso del río San Miguel -actual río Laja- hasta llegar a San Felipe; el otro doblaba hacia el norte, llegando al Paso de Jofre, seguía por los llanos de La Mohina y se unía con el otro camino cerca de San Felipe. De ahí, la ruta era el Portezuelo de San Felipe, Ojuelos, Encinillas, Las Bocas, Ciénega Grande y El Cuicillo, ${ }^{9}$ poblaciones destinadas a proteger a los transeúntes y las mercancías que por ahí pasaban hasta llegar a Zacatecas. (mapa 1)

5 Véase por ejemplo el libro Los Caminos de la Plata, de Aurelio de los Reyes, quien estudió este camino en el trayecto que va de Querétaro a Zacatecas, lo recorrió personalmente y acompañó su texto con fotografías de haciendas y de algunas construcciones abandonadas al paso de los siglos, ya que le interesó mostrar que esta ruta dejó como testimonio de su importancia una serie de edificaciones las cuales forman parte del patrimonio arquitectónico del Camino Real.

6 Cramaussel, "El Camino Real de Tierra Adentro", p. 299. Esta autora señala que el viaje entre la ciudad de México y Santa Fe - una distancia aproximada de $2500 \mathrm{~km}$ - duraba alrededor de 6 meses en el siglo XVII. A principios del siglo XIX el recorrido se hacía en cuatro meses y medio.

7 Servín, El Camino Real de Tierra Adentro. En esta obra, varios autores estudian el camino desde el punto de vista arqueológico e histórico; incluso toman en cuenta aspectos como las epidemias, la arquitectura, las técnicas de irrigación, la gastronomía y la lengua como elementos culturales que se desplazaron por esta ruta histórica.

8 Aunque las minas las descubrió Juan de Jasso entre 1552 y 1553, no las registró a su nombre. Fue hasta 1556 que Pedro Muñoz, maese de Roa, las redescubrió, y a partir de ese año varias personas comenzaron a registrar las minas. Jiménez Moreno, "La colonización y evangelización”, p. 92-94; Registro de las primeras minas de Guanajuato y Comanja 1556-1557, p. 15-16.

9 Powell, op. cit., p. 33. 


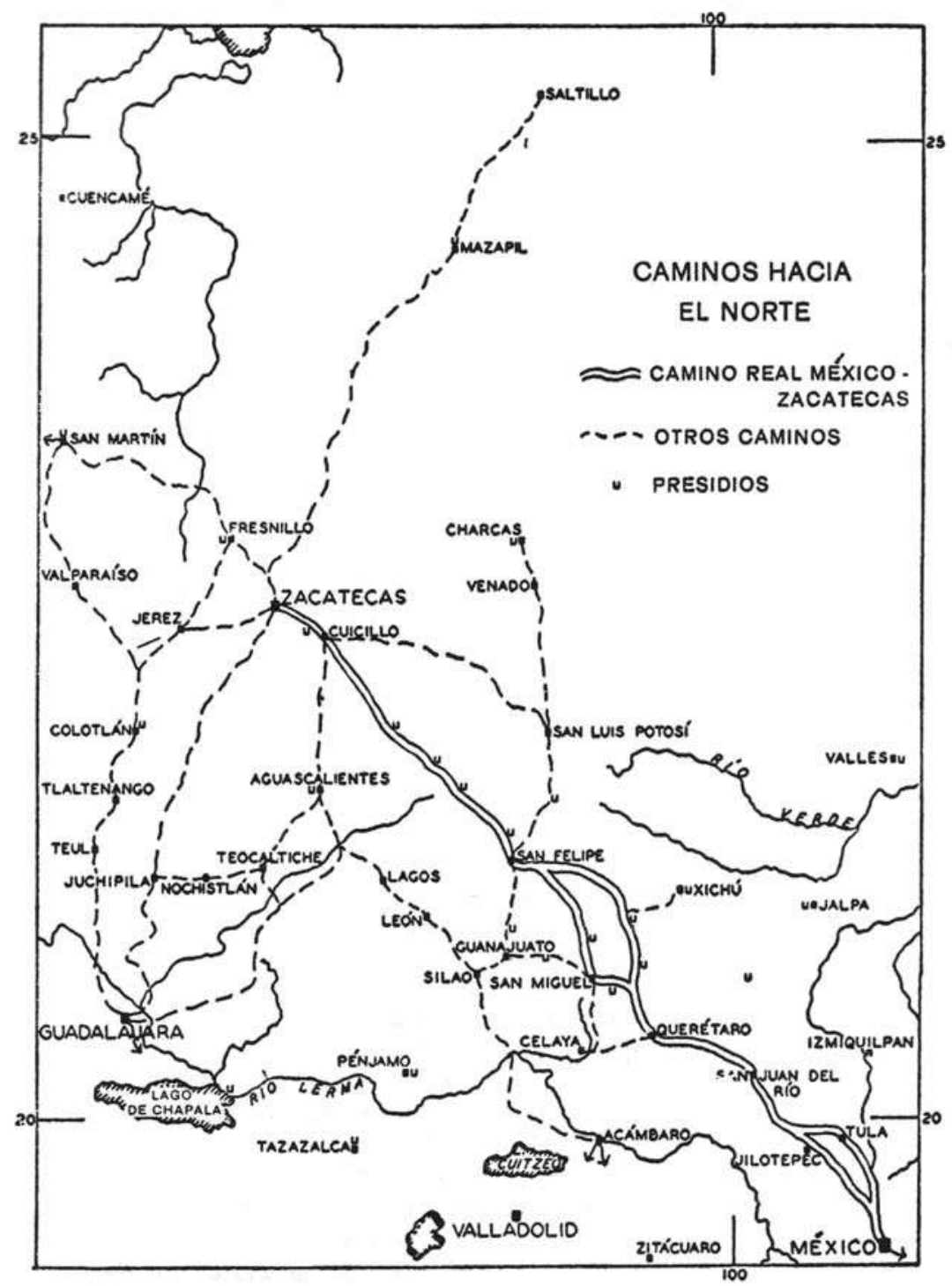

Mapa 1. Caminos hacia el norte. Tomado de Powell, La Guerra Chichimeca, p. 36. 


\section{2.- Colonización estanciera en el trayecto del Camino Real ${ }^{10}$}

El proceso de colonización a lo largo del Camino Real tuvo como una fase importante -además de la fundación de pueblos y villas-, la formación de estancias ganaderas y labores agrícolas, que fueron resultado de las donaciones o mercedes de tierra para ganado mayor y menor otorgadas en la región al norte del río Grande a partir de la década del 1540. ${ }^{11}$

Estas donaciones ${ }^{12}$ fueron un instrumento jurídico por el cual la corona española repartió las tierras de esta región, ya que no estaban sujetas al dominio de los mexicas ni de los pueblos otomíes y tarascos, sino habitadas por grupos chichimecas, por esta razón los españoles consideraron propicio su reparto al no pertenecer a pueblos agrícolas y sedentarios. Así, el gobierno virreinal comenzó a dar mercedes a quienes habían servido a la Corona en la conquista, exploración y pacificación de la Nueva España. Con ello, se premiaba su esfuerzo y, además, con la donación de mercedes poco a poco se fue trasladando el ganado a tierras septentrionales, ya que en el valle de México su aumento afectaba las sementeras de los indígenas, quienes se quejaban ante las autoridades porque el ganado invadía sus cultivos.

10 Por colonización estanciera me refiero al proceso de ocupación del territorio al norte del río Grande -Lerma- mediante la donación de mercedes de tierra para crear estancias ganaderas y labores agrícolas. Esta medida fue una de las varias estrategias de colonización que implementó el gobierno virreinal en esta región para atraer a pobladores, ganaderos, labradores e ir extendiendo la frontera española hacia el norte. Al respecto véase, Frausto, $\mathrm{La}$ colonización estanciera en la Nueva España; Pérez Luque, La tenencia de la tierra en la alcaldía mayor de León, 1542-1711.

11 Jiménez Moreno, "La colonización y evangelización", p. 76; respecto a la donación de mercedes y la formación de haciendas al norte del río Grande, en la actual zona del Bajío, pueden verse entre otras obras las siguientes: Brading, Haciendas y ranchos del Bajio; Baroni, La formación de la estructura agraria en el Bajío colonial; Pérez Luque, La tenencia de la tierra.

12 Las mercedes eran concesiones de tierra para sembrar o criar ganado. Se otorgaron para formar estancias de ganado mayor, ganado menor, caballerías, suertes de huerta y solares. La estancia para ganado mayor era un cuadrado que media 5,000 varas por lado y equivalía a $17.49 \mathrm{~km}^{2}$. La de ganado menor medía 3,333 varas por lado y tenía una superficie $7.76 \mathrm{~km}^{2}$. La caballería era un rectángulo, su lado mayor medía 1,104 varas y el menor 552 varas, siendo su superficie de $10.41 \mathrm{~km}^{2}$. Romero, "La agricultura en la época colonial", p.181. La suerte de huerta medía 10.68 hectáreas, y el solar, que era una porción de terreno destinada para casa, molino o venta, 0.1755 hectáreas. Santa Cruz y Giménez-Cacho, "Pesas y medidas en la agricultura”, p. 249. 
Los beneficiados por las mercedes tenían la obligación de trabajar las tierras, pero no todos conocían la que les era cedida, sobre todo los vecinos de la ciudad de México, quienes tenían administradores encargados de sus asuntos; además, la concesión no siempre significó la colonización inmediata por parte del titular, ya que era necesario trasladar el ganado desde el lugar donde se tenía hasta las nuevas propiedades recibidas y buscar trabajadores que comenzaran a labrar la tierra. ${ }^{13}$

En este proceso de colonización al norte del río Grande, en la zona entre Querétaro, San Miguel y San Felipe hubo dos elementos claves para solicitar y otorgar las mercedes: el río San Miguel y el Camino Real, que fue trazado en esta zona tomando como referente el curso del río.

Ambos elementos fueron tomados en cuenta en la donación de mercedes, pues era necesario tener acceso al agua para alimentar al ganado e irrigar las labores agrícolas; además, el Camino Real permitía al dueño de una estancia o labor cercana a esta ruta obtener insumos de comerciantes y arrieros que pasaban por ella; a su vez, esta vía le permitía sacar la producción y dirigirla a los lugares de consumo como Zacatecas o Guanajuato.

El Camino también fue un referente para establecer mesones o ventas donde se podía pernoctar, descansar, alimentarse o abastecer de insumos a las caravanas que iban o venían del norte, particularmente en espacios donde las jornadas eran largas o los tramos inseguros. Además, al funcionar como centros de aprovisionamiento, se evitaba que los viajeros quitaran por la fuerza alimentos e insumos a la población indígena o a los dueños de las estancias ubicadas en el trayecto. ${ }^{14}$

Como ejemplo del interés existente por obtener una propiedad cerca del Camino Real y sacar provecho con fines mercantiles, podemos señalar el caso de los franciscanos de San Miguel, quienes el 2 de mayo de 1550 recibieron una merced para establecer un sitio de venta en el camino a Zacatecas, a cinco leguas de distancia del pueblo de San Miguel y a un costado del río San Miguel, donde pusieron una cruz como señal de posesión. ${ }^{15}$ Otro

13 Quienes recibían las mercedes tenían el compromiso de poblarlas y trabajarlas por algunos años y no venderlas ni cederlas por algún tiempo, medidas que tomó la autoridad ya que esto promovía la colonización y mantenía la presencia de personas y ganado en la región.

14 Powell, op. cit., p. 37.

15 Archivo General de la Nación (AGN), Mercedes, vol. 3, f. 53v-54. 
ejemplo es el caso de Cristóbal de Oñate, ${ }^{16}$ quien recibió una merced para establecer una venta en el camino a Zacatecas, cinco leguas adelante del sitio que ese mismo día obtuvieron los franciscanos de San Miguel. ${ }^{17}$

En el mismo contexto están los ejemplos de Bartolomé Gómez y Juan Xaramillo, vecinos de la ciudad de México. El 10 de septiembre de 1550, Gómez recibió merced para un sitio de venta en el camino a Zacatecas, entre los pueblos de Querétaro y San Miguel; ${ }^{18}$ por su parte, Xaramillo recibió merced para tres sitios de venta en dicho camino el 25 de octubre de $1550 .{ }^{19}$

También, como ejemplo de que los sitios para ventas se siguieron otorgando en la región, podemos citar el caso de Alonso de San Vicente, quien el 23 de enero de 1564 recibió como merced un sitio de venta con una caballería de tierra junto al río Santa Catalina, afluente del río San Miguel. ${ }^{20}$

Además del Camino Real, otro referente geográfico para seguir la ruta al norte fue el río ubicado entre San Miguel y San Felipe. En algunas mercedes se menciona al río como elemento a considerar para otorgar las tierras, como lo podemos ver en los siguientes ejemplos.

El primero es una merced otorgada a Juan de Jasso el 21 de marzo de 1551, para establecer una estancia junto al río San Miguel, cerca del sitio de los herederos de Luis Marín". ${ }^{21}$ El segundo ejemplo es el de Diego Pérez, vecino de San Miguel, quien en junio de 1555 recibió una merced para estancia de ganado menor y una caballería de tierra entre dos caminos que salían de ese pueblo. ${ }^{22}$ El tercer ejemplo es el de Esteban García, vecino de San Felipe, quien en diciembre de 1562 recibió una merced para estancia de ganado menor en un sitio llamado La Quemada, ubicado junto al río que va a San Miguel y a un costado del Camino Real. ${ }^{23}$ Un ejemplo más es el

16 Oñate fue teniente de gobernador de Nueva Galicia, alentó las exploraciones en busca de yacimientos de plata, fue conocido como uno de los fundadores de Zacatecas y tuvo intereses y vínculos económicos en la ciudad de México. Bakewell, Minería y sociedad, p. 22-25.

17 AGN, op. cit., vol. 3 f. 54-54v.

18 Gerhard, Sintesis e indice de los mandamientos virreinales, 1548-1553, p. 370.

19 Ibíd., p. 373. Xaramillo participó en la conquista de México y fue encomendero de Jilotepec.

20 AGN, op. cit., vol. 7, f. 263-263v.

21 Ibid., vol. 3 f. $297 \mathrm{v}$. Este mismo día Jasso recibió cuatro mercedes más para establecer sitios de estancia en la sierra de Comanja. AGN, Mercedes, vol. 3 f. 298.

22 AGN, Tierras, vol. 803, f. 202.

23 Archivo Histórico de la Universidad de Guanajuato (AHUG), Ramo: Tierras, Lugar: San Felipe, Títulos de la Hacienda de la Quemada, Libro II, foja sin número ubicadas entre las fojas 41 y 42 . 
de Basco Fernández, quien recibió merced para un sitio de ganado menor junto a unos ojos de agua cerca del Camino Real, en la zona entre San Felipe y la villa de Santa María de los Lagos. ${ }^{24}$ Finalmente, otro ejemplo que nos muestra que los pobladores de la villa de San Felipe también participaron en el proceso de colonización estanciera de la región, es el de Juan Rico de Rojas, "el mozo", quien en calidad de vecino de esta villa recibió, el 4 de septiembre de 1582, un sitio para estancia de ganado menor junto a un cerro, en una cañada cercana al camino que comunicaba a San Felipe con el Valle de San Francisco. ${ }^{25}$

\section{3.- La fundación de San Miguel y su relación con el Camino Real}

Si el Camino Real y el río San Miguel fueron los elementos principales que se tomaron en cuenta para establecer estancias y labores agrícolas, también lo fueron para elegir el lugar donde se fundarían las villas de San Miguel, en 1555, y de San Felipe, en 1562.

La villa de San Miguel nació como pueblo gracias a las labores de evangelización de fray Juan de San Miguel, franciscano que salió del convento de Acámbaro y quien, en compañía de algunos indios tarascos, llegó hasta una zona donde, en 1542, ${ }^{26}$ aproximadamente, formó el pueblo de San Miguel, lugar que desde sus inicios fue de vital importancia para la colonización y pacificación de la región y para congregar a chichimecas junto con otros grupos indígenas, como lo señaló fray Guillermo de Santa María, quien apuntó que en esta villa había chichimecas guamares junto a otomíes y tarascos". ${ }^{27}$

Una vez que fray Juan de San Miguel regresó a Acámbaro, la atención espiritual quedó a cargo del franciscano fray Bernardo Cossin, ${ }^{28}$ quien

24 AGN, op. cit., vol. 130, f. 131

25 Ídem.

26 Gerhard, Geografía bistórica de la Nueva España, p. 244; Jiménez Moreno, La colonización y evangelización, p. 77. Sobre los antecedentes históricos de la villa, la participación de los otomíes en la colonización de esta región y el contexto documental de su fundación, véase Wright, La conquista del bajio y los origenes de san Miguel de Allende.

27 Santa María, Guerra de los Chichimecas, p. 219. Guillermo de Santa María fue un fraile agustino que evangelizó en la villa de San Felipe en la década de 1570. Es el autor del texto conocido como Guerra de los Chichimecas, atribuido a Gonzalo de las Casas y en el cual se basó Philip Powell para escribir sobre esta guerra. 
en 1548 declaró ante los procuradores de Vasco de Quiroga que había bautizado a los chichimecas de San Miguel, les había dado mantas y que había entre ellos naguatlatos de lengua tarasca. ${ }^{29}$

La integración de los chichimecas con grupos sedentarios en la villa de San Miguel fue una de las estrategias realizadas por las autoridades para alcanzar la pacificación. Esta medida se puso en marcha, como lo vemos por un mandato que se le dio a Juan de Villagómez, Justicia en los Chichimecas, ${ }^{30}$ el 6 de junio de 1551, para que congregara a indios chichimecas en San Miguel y trajera piedra y materiales para la construcción del monasterio de San Francisco". ${ }^{31}$

La presencia de chichimecas en San Miguel la vuelve a referir fray Guillermo de Santa María, quien señaló el ataque de un grupo de guamares que llegaron a un poblado cercano a San Miguel y mataron a 14 o 15 personas, razón por la cual los chichimecas, tarascos y otomíes que se encontraban en el lugar lo abandonaron; ${ }^{32}$ sin embargo, la zona no se despobló por completo.

Fue hasta el 15 diciembre de 1555 cuando el virrey Luis de Velasco comisionó a Ángel de Villafañe, hombre de su confianza y vecino de la ciudad de México, para fundar la villa de españoles de San Miguel en el sitio y lugar que mejor le pereciera. La fundación se ordenó para que terminaran las muertes y robos en los llanos de San Miguel, en el camino a Zacatecas, y para llevarla a cabo, se le pidió a Villafañe que fuera:

28 Fray Bernardo Cosín murió alrededor de 1556, a manos de un grupo de chichimecas. Santa María, Guerra de los Chichimecas, p. 200. Morales, "Los franciscanos y la frontera chichimeca", en Carillo Cázares (ed) La guerra y la pa\%. Tradiciones y contradicciones de nuestra cultura, p. 313.

29 Román Gutiérrez, Sociedad y evangelización, p 199. Los procuradores del obispo Quiroga recogieron testimonios de Cossin y de algunos pobladores de la región, para argumentar que las estancias ubicadas el norte del rio Grande estaban en la jurisdicción eclesiástica de Michoacán y no en la de Nueva Galicia, cuyo Obispo, Pedro Gómez de Maraver, pretendía extender su jurisdicción hasta esta zona y tener el derecho a cobrar los diezmos de las estancias.

30 Quien ocupaba el cargo de Justicia en los Chichimecas se encargaba del gobierno en la frontera y de la defensa de los ataques chichimecas. Su jurisdicción se extendía desde Jilotepec hacia el norte, llegando a las fronteras de Nueva Galicia y San Luis Potosí. Gerhard, Geografía bistórica, p. 393.

31 Paredes, Y por mi visto. Mandamientos, ordenanzas, p. 61, documento 63.

32 Santa María, Guerra de los Chichimecas, p. 222 
al dicho pueblo de San Miguel que se está comenzando a poblar de españoles y llegando a él, veas el sitio y en la parte que pareciere que estará bien la dicha villa de los españoles, la señales y traces por la orden que más convenga, de manera que vivan en toda policía y buena traza, y en la dicha parte les señales solares de casas, huertas y tierras para labranzas y crianzas de hasta cincuenta españoles... las tierras solares y huertas han de ser fuera de las casas de los indios tarascos chichimecas y otomies que en el pueblo viven y de las sementeras que tienen, de manera que los unos y los otros tengan sus tierras distintas y apartadas...hecho en la estancia de Apaseo a quince de diciembre de mil quinientos cincuenta y cinco años. ${ }^{33}$

En este documento vemos dos elementos importantes para entender el contexto de fundación de la villa de San Miguel. Primero, ya había indios establecidos en el lugar, quienes, además de tener fijados los límites de sus sembradíos, desarrollaban la agricultura aprovechando la cercanía del río San Miguel y las condiciones geográficas de la zona; segundo, este documento $-\mathrm{y}$ un mandato más, ${ }^{34}$ emitido tres días después, el 18 de diciembre- muestra que la principal intención de la fundación de la villa era la pacificación de la región en el contexto de la guerra chichimeca y en el trayecto del camino a Zacatecas. Por ello se especificó que la fundación se hacía para que cesaran los robos y muertes en dicha ruta.

Esta situación se repitió en el caso de la villa de San Felipe, fundada el $1^{\circ}$ de enero de 1562 por orden de Luis de Velasco, quien comisionó a su hermano, Francisco de Velasco, para llevar a cabo dicha acción. Como se puede ver en el documento de fundación de San Felipe, ${ }^{35}$ el objetivo de esta villa era contribuir a la pacificación de la región, así como brindar seguridad a los transeúntes y caravanas que iban o venían de Zacatecas.

La fundación de las villas de San Miguel y San Felipe no acabó con

33 AGN, Mercedes, vol. 4 f. 280v-281. En la transcripción se actualizó la ortografía y el vocabulario.

34 Ibíd., vol. 4 f. 286-286v. El segundo mandato fue expedido el 18 de diciembre de 1555, en el que se ordena enviar diez indios de servicio del pueblo de Guango, dieciséis de Acámbaro, ocho de Querétaro y dieciséis de Cuiseo a San Miguel para ayudar a construir las casas del lugar. Este documento ha sido publicado en: Rubio Mañé, Titulos de las villas de san Miguel el Grande y San Felipe, p. 339; Wright, La conquista del Bajio, apéndice 1, p. 75-76.

35 agn, Documentos para la bistoria de la villa de San Felipe, vol. único, sin foja. 
los ataques de los chichimecas, pero su poblamiento permitió al gobierno español ganar poco a poco el territorio y defender la frontera de guerra la cual se recorrería más al norte, según se iban formando villas o estancias a lo largo del camino a Zacatecas.

Mediante los documentos del 15 y 18 de diciembre de 1555 se ordenó la fundación jurídica de la villa de San Miguel, pero estos documentos no son el título de la misma, el cual se emitió hasta el 17 de diciembre de $1559 .{ }^{36}$ En él se señala que algunos españoles, a quienes les han dado tierras, huertas y solares donde vivir, se han avecindado en el pueblo con licencia del virrey, separados de las tierras de los indígenas, como lo podemos ver en el mapa 2, elaborado en 1591, donde se muestra la ubicación estratégica de la villa de San Miguel cerca del río, esto posibilitó el desarrollo de la agricultura, la ganadería y el sustento de los pobladores, mientras la cercanía del Camino Real propició la comunicación con el centro y norte de la Nueva España.

\section{4.- El Camino Real en el norte de Guanajuato: una descripción del mapa de San Miguel y San Felipe, 1580.}

Este camino, cuya finalidad era fungir como ruta a las minas de Zacatecas, también se volvió ruta de pacificación y colonización, pudiéndosele llamar además ruta comercial, colonizadora y defensiva, ${ }^{37}$ pues, en su trayecto, soldados y capitanes realizaban expediciones en busca de chichimecas alzados a quienes arrestar.Un ejemplo es el de Pedro de Ahumada, comisionado para realizar una campaña de castigo y pacificación de los chichimecas en el año de $1561 .^{38}$

Además, para controlar la frontera a lo largo del Camino Real, se construyeron varios de los presidios los cuales fueron puntos estratégicos durante la guerra. Sobre este tema, Powell señala que el camino a Zacatecas fue

36 AGN, Media Anata, vol. 35, f. 244-249v. Ha sido publicado por Rubio Mañé, Títulos de las villas de San Miguel el Grande y San Felipe, p. 343-353 y Wright, La conquista del Bajio, apéndice 2 , p. $77-83$.

37 Florescano, Colonización, ocupación del suelo y frontera en el norte de la Nueva España, p. 47.

38 "Relación de Pedro de Ahumada Sámano", en Carrillo Cázarez, El Debate sobre la guerra chichimeca, vol. II, documento 25, p. 563-574. 


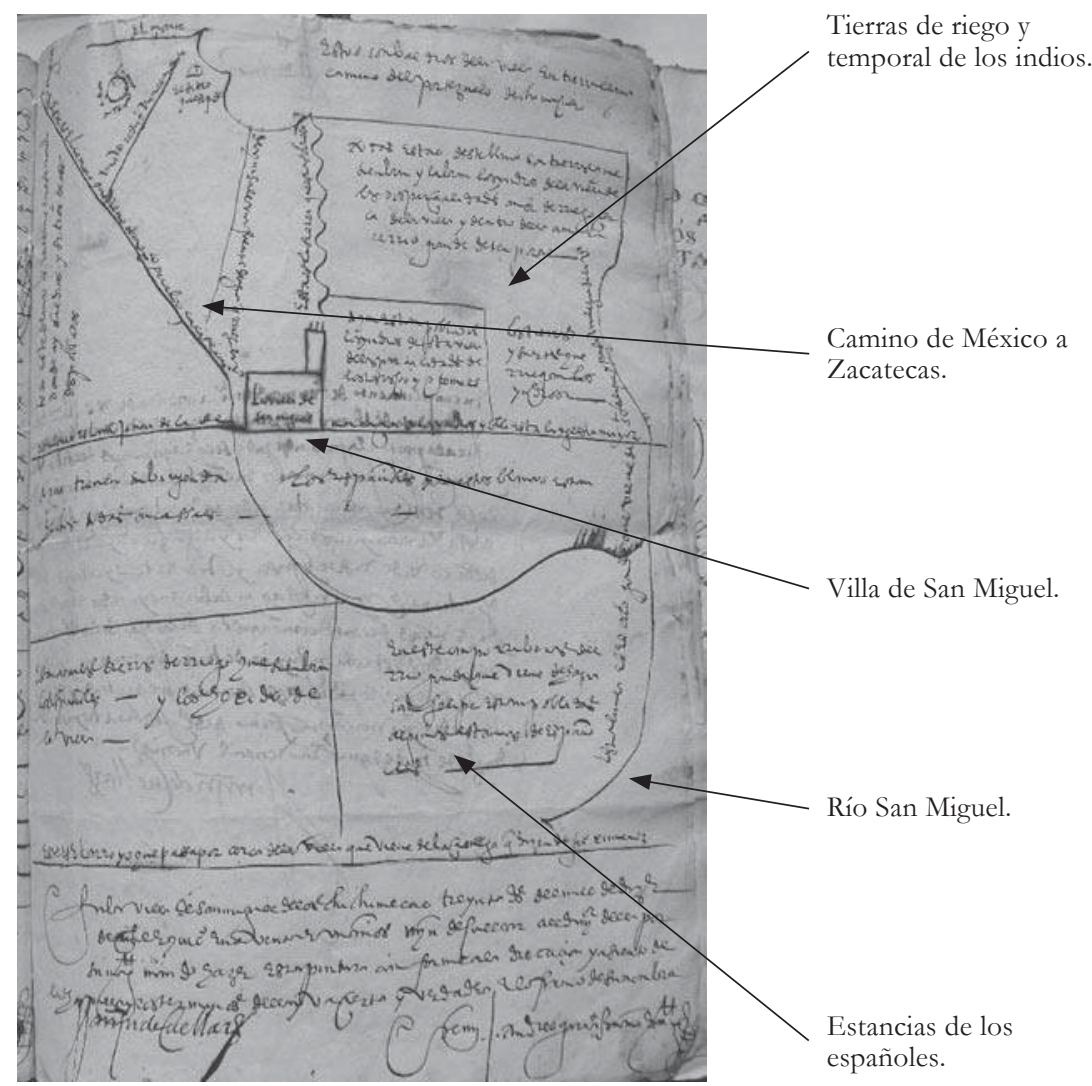

Mapa 2. AGN, Tierras, vol. 2713, exp. 2 f. 6. Año de 1591

el blanco favorito de los chichimecas, -aunque, más bien, el blanco fueron las carretas cargadas de insumos y alimento, mientras que el camino fue el escenario principal de los enfrentamientos armados-, razón que llevó al virrey Enríquez de Almanza a crear los fuertes o presidios, con soldados quienes servían de guarnición y escolta, y siendo los primeros en construirse los de Portezuelo y Ojuelos, al noroeste de San Felipe, cuya construcción fue encomendada al Alcalde Mayor de Jilotepec. ${ }^{39}$

Este camino fue de vital importancia para colonizar la región entre

39 Powell, “Génesis del presidio como institución fronteriza, 1569-1600”, p. 23-24. 
Querétaro y Zacatecas, ya que en su trayecto se establecieron las villas de San Miguel y San Felipe. Además, se trazaron caminos secundarios cuya función era comunicar la ruta principal con otros lugares cercanos como las minas de Guanajuato, el valle de San Francisco y la Sierra Gorda a través de Sichú.

Como ejemplo del avance español rumbo al norte de la Nueva España, además de la documentación escrita tenemos el mapa de San Miguel y San Felipe, de 1580 aproximadamente (mapa 3), este posiblemente acompañaba a la Relación geográfica de la alcaldía mayor de San Miguel, documento perdido el cual formó parte del corpus de relaciones geográficas elaboradas a petición de la Corona entre 1579 y 1582 para informar sobre la situación de los territorios de la Nueva España. Al estar perdida la relación que corresponde a San Miguel, el mapa se vuelve aún más valioso, porque en él se describe la situación de esta región alrededor de 1580.

En este mapa ${ }^{40}$ aparecen caminos, villas, estancias, ríos, ojos de agua, cerros, fauna, flora, y se ejemplifica la situación de frontera de guerra y frontera cultural establecida en esta región entre españoles y chichimecas. Para los objetivos de este trabajo lo dividí en cuatro secciones, aunque me centraré sólo en las dos superiores, donde se encuentra el camino a Zacatecas y el río San Miguel. Comenzaré con la parte superior izquierda del mapa.

Esta parte representa la guerra de los chichimecas y la defensa de su territorio. Aparecen dibujados nopales, tres chozas y un par de chichimecas junto a ellas, detalle que indica un lugar de asentamiento temporal, ya que eran de tradición nómada.

Se nota, además, que la ruta a Zacatecas y el río San Miguel corren paralelos en esta zona, donde vemos a algunos chichimecas escondidos, posiblemente esperando atacar en los costados del camino. La representación y ubicación de éstos en el mapa es interesante, debido a que muestra que uno de los lugares de ataque estaba cerca de los cerros, en los pasos obligados

40 La copia de esta mapa la tomé de Ruiz Guadalajara, Dolores antes de la independencia, p. 126131. Nieto también lo ha estudiado y señala que el original se encuentra en el Archivo de la Real Academia de la Historia de Madrid, con la siguiente ubicación: (Expediente núm. XIII- LA VILLA DE SAN MIGUEL Y SU JURISDiCCIÓN Academia de la Historia -Relaciones GeográficasCarpeta 16.9/4663). Nieto, San Miguel de Allende en el Camino Real de Tierra Adentro, p. 174. El mapa también ha sido publicado por Jiménez Moreno, Estudios de Historia Colonial y Aurelio de los Reyes, Los Caminos de la Plata. 
y peligrosos como los puertos de Jofre, de Nieto o Chamacuero, donde los chichimecas podían huir en caso de que los persiguieran, sobre todo porque, en un principio, no sabían usar caballo, gran desventaja respecto a los soldados quienes venían cabalgando.

Se muestran también la villa de San Felipe en el camino que sale hacia la sierra de Guanajuato y los ojos de agua cercanos al lugar. El pintor conocía la zona, pues al señalar la ubicación de San Felipe, la colocó a un costado del camino a Zacatecas y sobre uno de los arroyos que salen de los ojos de agua, conocidos como Ojos Zarcos. La ubicación de estos manantiales influyó la fundación de San Felipe, que así quedaría abastecida del vital líquido en una zona como ésta, con poca lluvia y un clima seco gran parte del año.

También vemos que de San Felipe, rumbo al sur, sale el camino a Guanajuato el cual atraviesa la sierra y del que actualmente quedan algunos tramos, aunque cada vez menos usados gracias a la carretera de terracería que lo ha sustituido. Finalmente, vemos una de las zonas más peligrosas en el camino: los fuertes del Portezuelo, de Ojuelos y de las Bocas, estos estaban estratégicamente ubicados en una zona de ataque de chichimecas. Su función era tanto resguardar las caravanas que iban o venían como proteger la villa de San Felipe.

La peligrosidad de esta zona es señalada claramente por Guillermo de Santa María en el texto mayor de la Guerra de los Chichimecas. En la parte correspondiente al inicio de la guerra apuntó que:

los guachichiles, por otra parte, en este mismo tiempo, también comenzaron a hacer daño y lo hicieron en un arria de Diego Alonso de Pedroso, en el camino nuevo que va de los ojos Zarcos a salir donde ahora es San Felipe. Mataron al arriero, y esto fue el año de 1550. Luego el año de cincuenta y uno, por el mes de julio, hicieron estos mismos Guachichiles otro salto, en carretas de Cristóbal de Oñate y Diego de Ibarra, entre la Ciénega Grande y las Bocas. ${ }^{41}$

En la segunda parte del mapa (superior derecha) es notoria la presencia

41 Santa María, op. cit., p. 221-222. 
española por los soldados y el avance de la colonización mediante las estancias cercanas al río San Miguel. Vemos el camino de Querétaro a San Felipe que rodeaba por el norte y pasaba cerca de donde después se establecería San Luis de la Paz.

Notamos las estancias cercanas al río, el cual se volvió un referente geográfico importante, ya que en una zona seca como ésta era necesario utilizar agua para el desarrollo de la agricultura y la ganadería. Además, insisto, el río -y no solamente el camino- se volvió una ruta de colonización, y como ejemplo de ello están las estancias dibujadas a su costado, donde se encuentra el siguiente texto: "todas las casas que están ribera de este río son estancias de vacas y algunas labranzas". Esta característica llamó la atención del obispo de Michoacán, Baltasar de Covarrubias, quien en 1619, al describir la villa de San Miguel, apuntó que había "27 estancias en los llanos y vegas del río que va a dar a Celaya". ${ }^{42}$

Vemos también soldados, estancieros y carretas en dirección a San Felipe. Esta parte es importante para entender la situación de frontera y de guerra chichimeca. Se representaron cuatro soldados vestidos con armaduras y mallas los cuales cubren su rostro. Los cuatro montan caballos que van protegidos con capa color café; Los cuatro llevan rifle, pero los de la parte superior fueron pintados disparando su arma, -según se entiende por las líneas representadas en la punta de los cañones-, detalle que no fue dibujado en los soldados de la parte inferior. Ello muestra el proceso de la guerra y la necesidad de proteger las caravanas que pasaban por el camino.

En esta parte del mapa, junto a las carretas, aparecen dos estancieros estos llevan sombrero, barba y unas lanzas o varas, seguramente para arrear a los cuatro bueyes que jalan las carretas y que fueron dibujados justo sobre le línea roja que indica el camino a San Felipe.

Finalmente se ve la villa de San Miguel, y cerca se nota un círculo del cual brota agua para formar un arroyo que va a dar hasta el río. Este dibujo parece representar un molino que aprovecha la fuerza del agua a su alrededor. Probablemente este molino fue construido por Diego de Beldiz, quien en junio de 1558, y en calidad de vecino de la villa de San Miguel, solicitó al

42 Covarrubias, Relación del obispado de Michoacán, p. 179. 
virrey se le dieran las tierras, solar y huertas que le correspondían, pero, además, se le dio merced de "un sitio de herido para molino de panmoler encima de la dicha villa, entre ella y la estancia de Juan Sánchez de Alanís". ${ }^{3}$

Como se puede ver, la dirección del mapa es de oriente a poniente y está marcada por los dos soles que fueron dibujados a los lados, uno rumbo a Querétaro y otro en rumbo a Ojuelos. Además, en todo el mapa aparece dibujado el ganado traído por los españoles que para 1580 ya se encontraba disperso por la región.

Podemos observar en el mapa de San Miguel y San Felipe que hubo rutas más cortas que comunicaban la vía principal con otros puntos de la zona. Por ejemplo, el camino que iba de Guanajuato a San Felipe atravesaba la sierra y salía junto al potrero de Jasso. Otros caminos eran los que iban de San Miguel a Guanajuato y a Chamacuero. ${ }^{44}$ Además, al norte de San Felipe se indica la entrada al valle de San Francisco, ${ }^{45}$ y del lado superior derecho del mapa se señaló el rumbo que conducía hasta el pueblo de Sichú, en la Sierra Gorda.

43 AGN, Mercedes, vol. 84, exp. 68, f. 30-30v.

44 Actual municipio de Comonfort, en el estado de Guanajuato.

45Actual municipio de Villa de Reyes, en el estado de San Luis Potosí. 


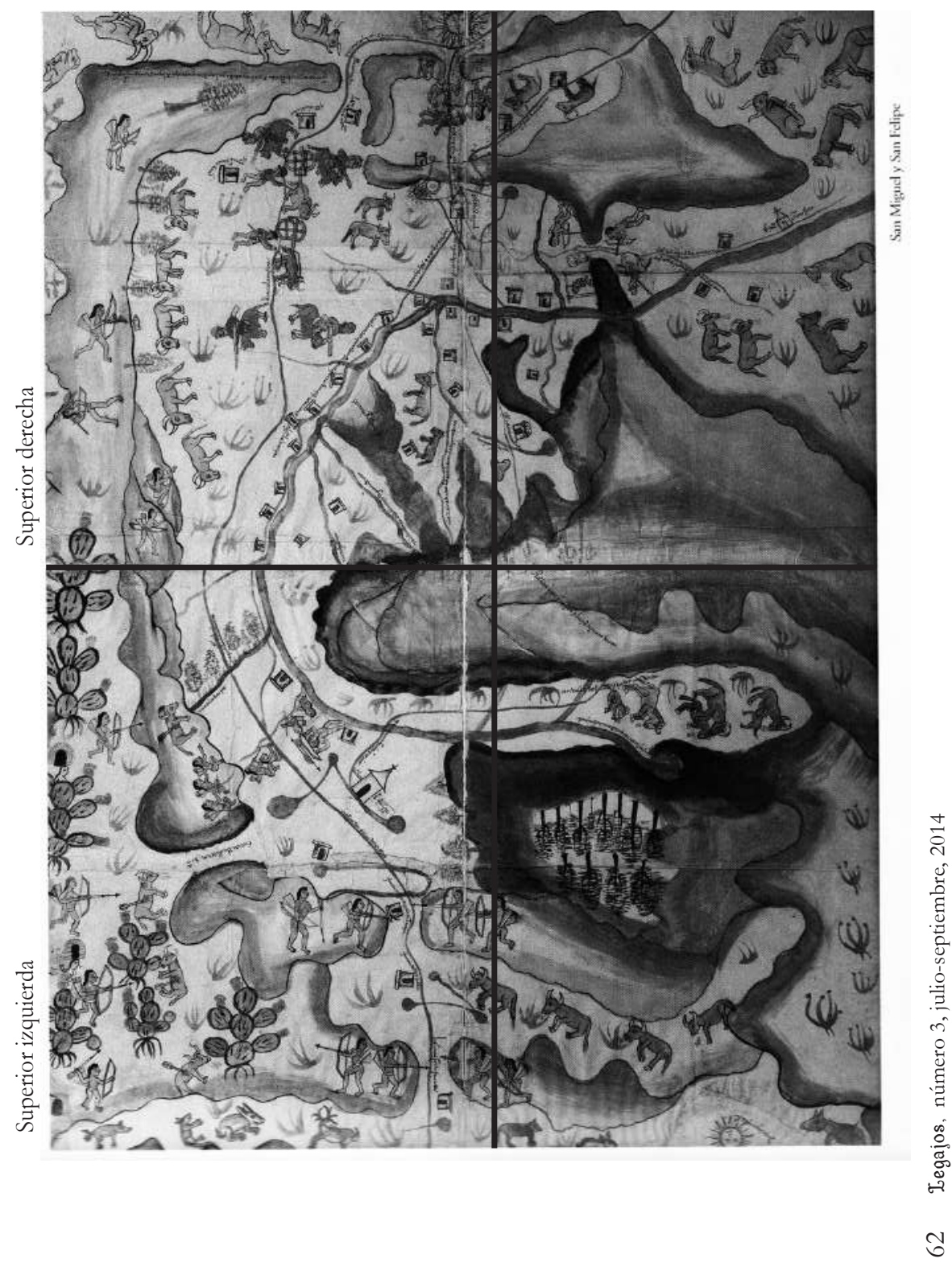




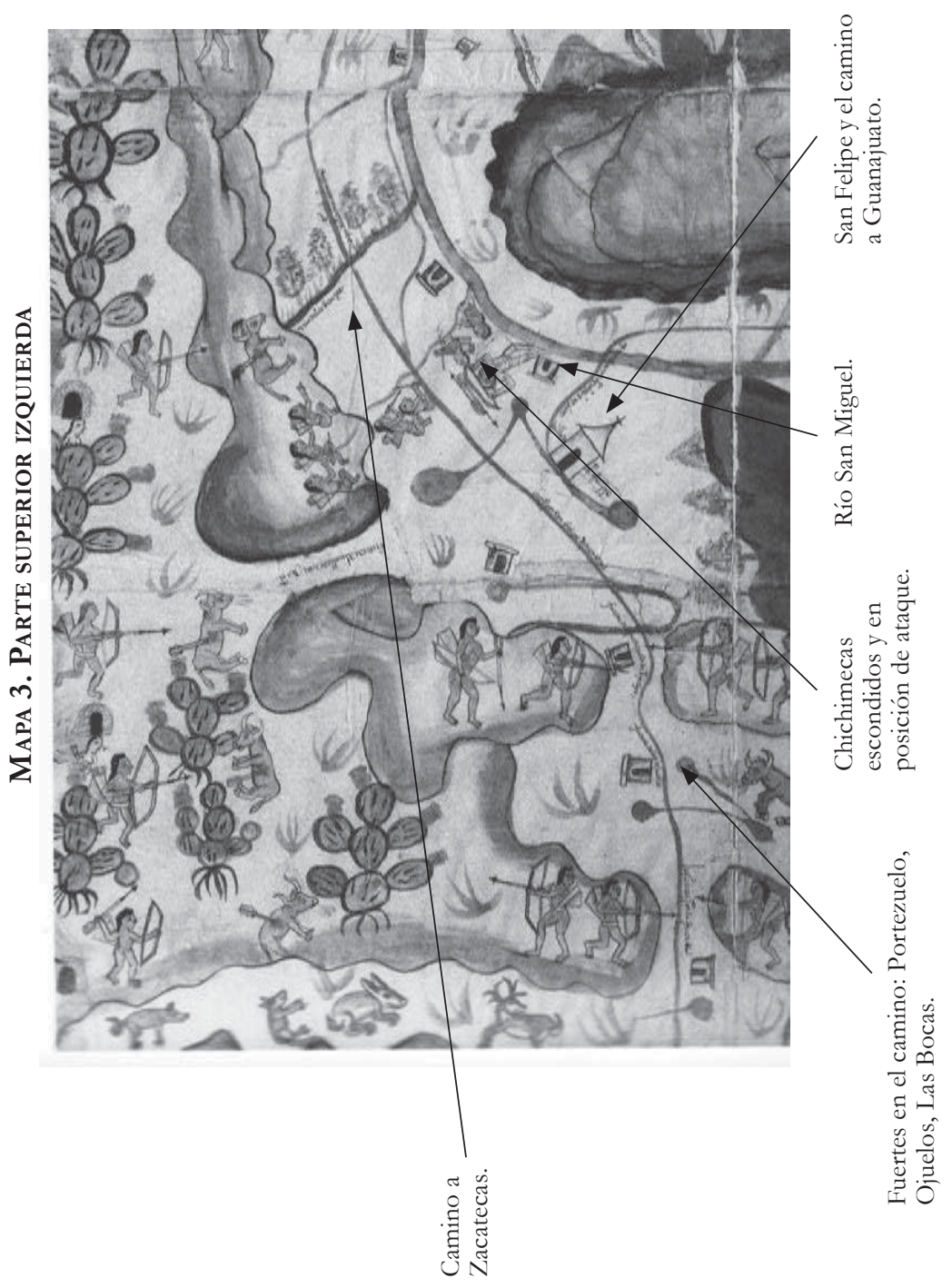




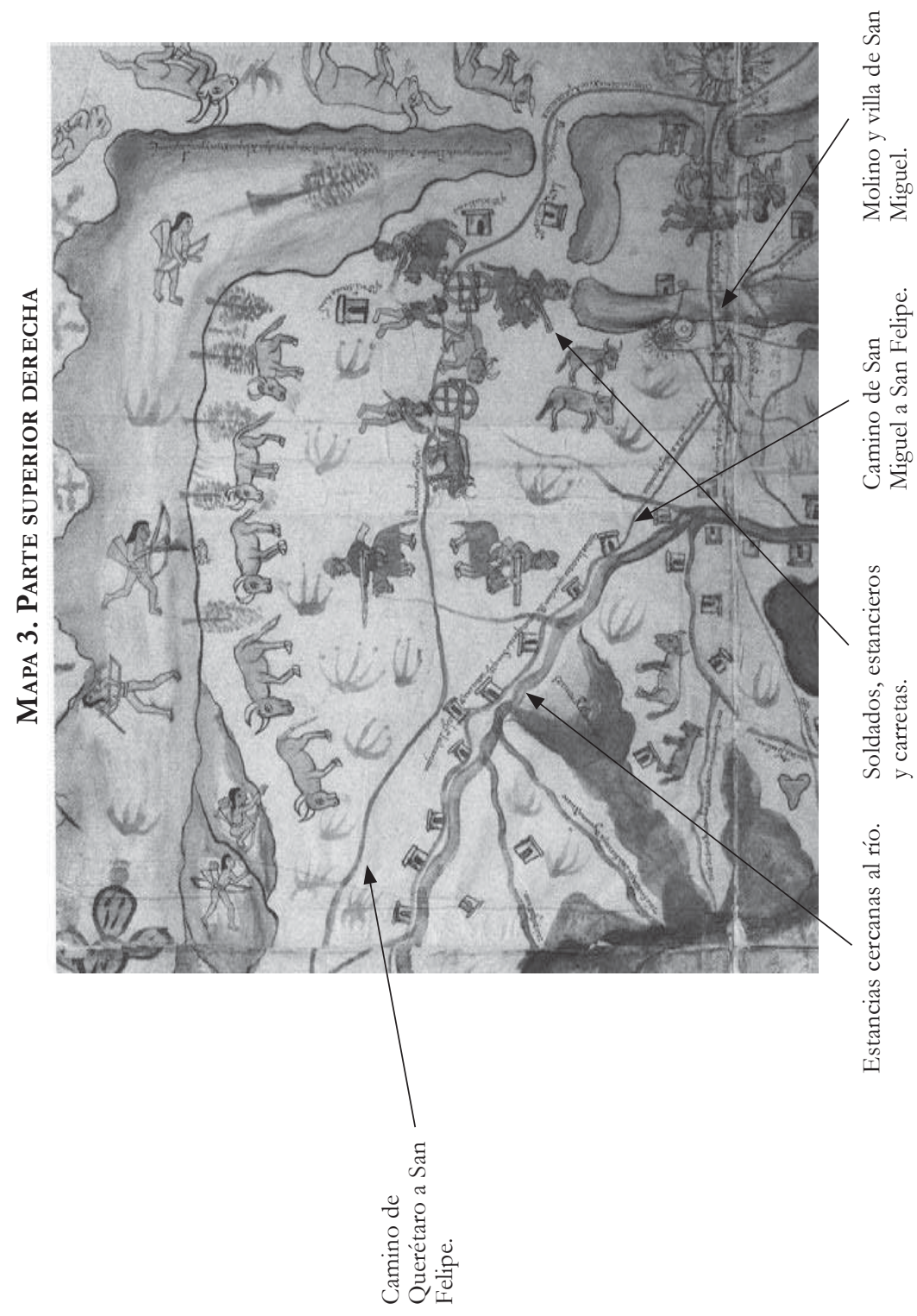

ปे 
Durante el periodo virreinal, el Camino Real siguió siendo la vía principal para llegar a tierras septentrionales; sin embargo, el tramo correspondiente a Querétaro, San Miguel y San Felipe fue perdiendo importancia a fines del siglo XVIII, al verse desplazado por la ruta que pasaba por Querétaro, Celaya, León, Lagos y Aguascalientes, hasta llegar a Zacatecas -la cual atravesaba el Bajío y permitía hacer un recorrido por tierras menos agrestes.

Este trayecto, que podemos llamar la ruta del Bajío, se volvió importante en el siglo XVIII porque era la vía para llegar y salir de la ciudad de Guanajuato, real minero que tuvo su auge en este siglo y que absorbía mucha de la producción agrícola de las haciendas de la región. ${ }^{46}$ Además, por esta ruta se iba a la ciudad de Guadalajara ${ }^{47}$-sede de la audiencia y del obispado de Nueva Galicia- y a San Juan de los Lagos, punto importante de peregrinaje, donde se realizaba una gran feria comercial a la que acudían arrieros y demás comerciantes para ofrecer sus productos.

Aunado a ello, la guerra de independencia afectó la producción comercial e industrial del Bajío. Las minas se inundaron y muchos de los trabajadores del campo y de los talleres textiles se fueron a la guerra, abandonando sus lugares de trabajo y afectando con ello el desarrollo comercial y económico del Bajío y de las villas de San Miguel y San Felipe. La guerra trajo inestabilidad política, falta de recursos económicos y deterioro de muchos caminos que se volvieron peligrosos por los constantes asaltos de bandidos.

A mediados del siglo XIx la situación de los caminos no había mejorado, ${ }^{48}$ aunque se promovieron esfuerzos para reparar algunas rutas buscando con ello reactivar la economía y el comercio. ${ }^{49}$ El último factor que contribuyó al abandono del Camino Real en la jurisdicción de las villas de San Miguel y San Felipe fue la llegada del Ferrocarril Nacional Mexicano ${ }^{50}$ a esta región

46 Cramaussel señala el auge minero de Guanajuato como una de las causas del abandono del ramal que iba de Querétaro a San Miguel, San Felipe y San Luis Potosí. Cramaussel, art. cit., p. 315.

47 Castañeda señala que había dos rutas que comunicaban a la ciudad de México con Guadalajara. La septentrional, que pasaba por la región de Los Altos hasta llegar a San Juan de los Lagos, y la ruta meridional, que llegaba a Valladolid y seguía por el lago de Chapala hasta conectarse con Guadalajara. Castañeda, "Los caminos de México a Guadalajara", p. 263.

48 Álvarez y Duran, Itinerarios y derroteros, p. 239. Este es un texto que publicó el Estado Mayor del Ejército en el año de 1856, con el objetivo de conocer algunas rutas y sus condiciones físicas en distintas zonas del país.

49 Jáuregui, Los transportes, siglos XVI al xx, p. 49

50 Esta ruta fue controlada por la Compañía Constructora Nacional y comunicaba a la ciudad de México con Nuevo Laredo. Fue la segunda en extensión e importancia económica 
en el año de 1888. Aunque el tren mejoró las condiciones de comercio y conectó a diferentes haciendas y poblaciones, su llegada a esta zona alteró algunos tramos del Camino Real, ya que los rieles se colocaron sobre algunas partes del trayecto, por lo que la vieja ruta virreinal fue desplazada por la nueva ruta ferroviaria. (mapa 4)

y mercantil, superada sólo por el tren que iba de México a Ciudad Juárez, conocido como el Ferrocarril Central Mexicano, que pasaba por la zona del Bajío -Celaya, Irapuato, León- y se adentraba al norte por la ciudad de Aguascalientes. Sobre los ferrocarriles véanse, entre otras fuentes: Calderón, Los ferrocarriles; Kuntz, Los ferrocarriles y la formación del espacio económico en México, 1880-1910; Kuntz, Mercado interno y vinculación con el exterior, Ortiz, Los ferrocarriles en México. Una visión social y económica. 


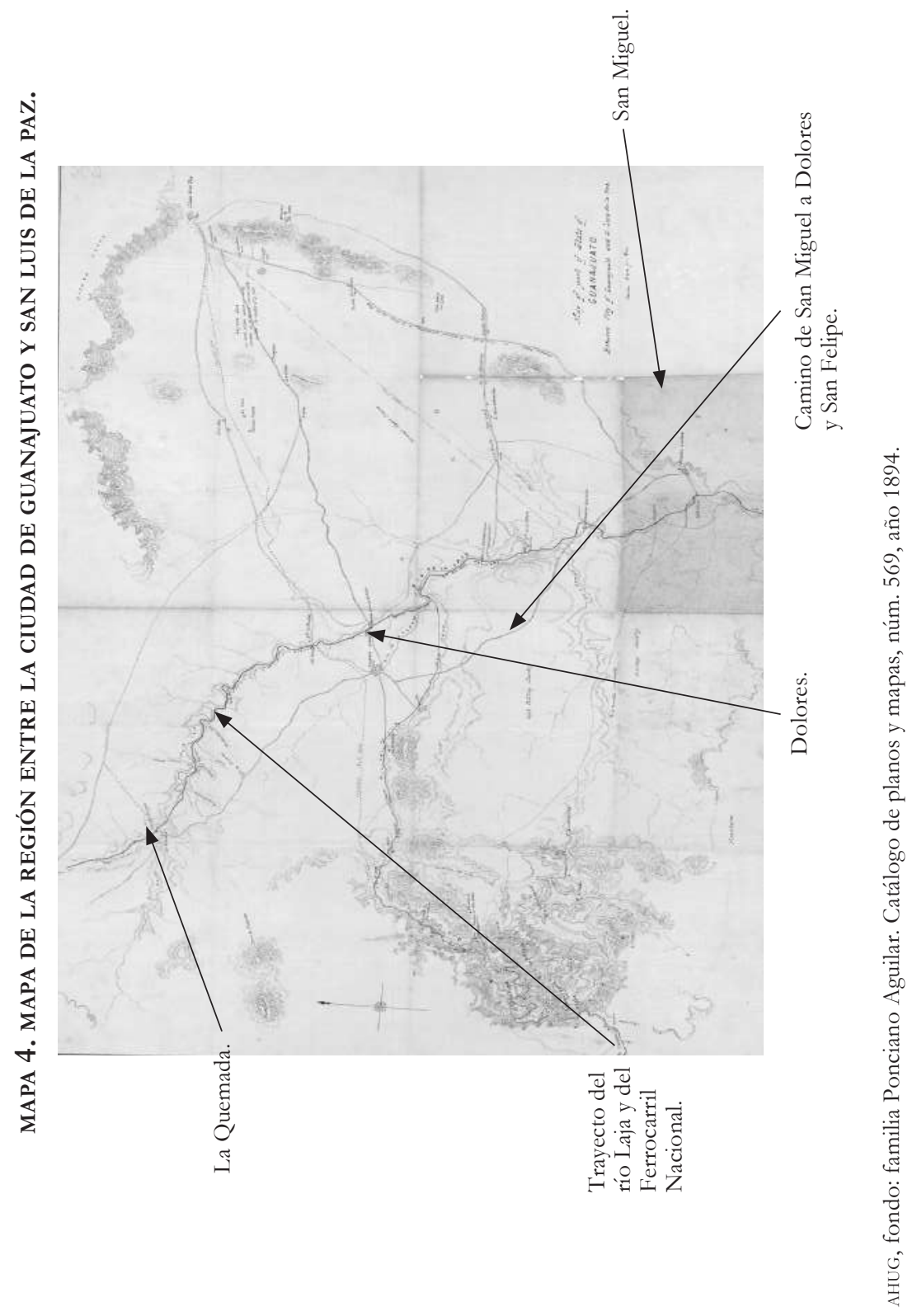




\section{Archivos}

Archivo General de la Nación. (AGN)

Archivo Histórico de la Universidad de Guanajuato (AHUG)

\section{Bibliografía}

Álvarez, José J. y Rafael Duran, Itinerarios y derroteros de la República mexicana publicados por los ayudantes del Estado Mayor del Ejército, México, Imprenta de José A. Godoy, 1856.

Bakewell, P.J., Minería y sociedad en el México colonial (1546-1700), México, Fondo de Cultural Económica, 1997.

Baroni, Boissonas, Ariane, La formación de la estructura agraria en el Bajío colonial. Siglos XVI y XVII. México, CIESAS, 1990.

Brading, David, Haciendas y ranchos del Bajío, León 1700-1860. México, Grijalbo, 1988.

Calderón, Francisco, "Los ferrocarriles”, en Daniel Cosío Villegas (coord.), Historia moderna de México. El porfiriato, la vida económica. Vol I, México, Editorial Hermes, 1965, pp. 483-634.

Castañeda, Carmen, "Los caminos de México a Guadalajara", en Cramaussel, (ed.), Rutas de la Nueva España. México, El Colegio de Michoacán, 2006, pp. 263-274.

Covarrubias, fray Baltasar de, "Relación de la diócesis de Michoacán hecha por el obispo...en Valladolid en 1619", en Ernesto Lemoine, (comp.) Valladolid-Morelia, 450 años. Documentos para su historia, Morelia, Morevallado editores, 1993, pp. 149-186. 
Cramaussel, Chantal, "El Camino Real de Tierra Adentro. De México a Santa Fe", en Chantal Cramaussel (ed.), Rutas de la Nueva España. México, El Colegio de Michoacán, 2006, pp. 299-327.

Florescano, Enrique, "Colonización, ocupación del suelo y frontera en el norte de Nueva España, 1521-1750”, en Álvaro Jara (ed.), Tierras Nuevas. Expansión territorial y ocupación del suelo en América (siglos XVI - XIX) México, El Colegio de México. 1969, pp. 43-76.

Gerhard, Peter, Sintesis e indice de los mandamientos virreinales, 1548-1553, México, Universidad Nacional Autónoma de México, 1992.

, La frontera norte de la Nueva España, México, Universidad Nacional Autónoma de México, 1996.

Geografía histórica de la Nueva España, 1519-1821, México, Universidad Nacional Autónoma de México, 2000.

Jáuregui, Luis, Los transportes, siglos XVI al XX, México, Universidad Nacional Autónoma de México/oceano, 2004.

Jiménez Moreno, Wigberto, "La colonización y evangelización de Guanajuato en el Siglo xvI”, en Wigberto Jiménez Moreno, Estudios de historia colonial. México, INAH, 1958, pp. 63-94.

Kuntz, Sandra, "Mercado interno y vinculación con el exterior: el papel de los ferrocarriles en la economía del porfiriato", en Historia Mexicana, vol. XLV, núm. 1, 1995, pp. 3965

Kuntz, Sandra y Priscila Connolly (coord.) Ferrocarriles y obras públicas. México, Instituto Mora/El Colegio de Michoacán/El Colegio de México/ Universidad Nacional Autónoma de México, 1999.

Morales, Francisco, "Los franciscanos y la frontera chichimeca. Experiencias, actitudes e ideas sobre la paz y la guerra en el territorio de frontera" en: 
Alberto Carrillo Cázares, La guerra y la paz: tradiciones y contradicciones de nuestra cultura. México, El Colegio de Michoacán, 2000, pp. 309-324.

Nieto Gamiño, Luis Felipe, "San Miguel de Allende en el Camino Real de Tierra Adentro", en López Morales, Francisco y Francisco Vidargas (ed.), Itinerarios culturales: Planes de manejo y turismo sustentable, México, Instituto Nacional de Antropología e Historia, 2011.

Ortiz Hernán, Sergio, Los ferrocarriles de México: una visión social y económica, México, Secretaría de Comunicaciones y Transportes, 1970.

Paredes Martínez, Carlos (ed), Y por mí visto... Mandamientos, ordenanzas, licencias y otras disposiciones virreinales del siglo XVI, México, CIESAS/Universidad Michoacana de San Nicolás de Hidalgo, 1994.

Pérez Luque, Rosa Alicia, "La tenencia de la tierra en la alcaldía mayor de León, 1542-1711". México, tesis de maestría en historia, UNAM, 2009.

Powell, Phillip, La Guerra Chichimeca (1550-1600), México, Fondo de Cultura Económica, 1985.

, "Génesis del presidio como institución fronteriza, 15691600", en: Estudios de Historia Novohispana. Vol. 9, 1987, pp. 19-36.

Registro de las primeras minas de Guanajuato y Comanja, 1556-1557, México, Archivo del Estado de Guanajuato, Introducción de Isauro Rionda Arreguín, 1992.

"Relación de Pedro de Ahumada Sámano", en Alberto Carrillo Cázarez, El Debate sobre la guerra chicbimeca, 2 vols. Zamora, El Colegio de Michoacán/El Colegio de San Luis, 2000.

Reyes, Aurelio de los, Los caminos de la plata, México, Gobierno del estado de Zacatecas/Patronato de Minería Cinco Siglos en México/Universidad Iberoamericana, 1991. 
Rodríguez Frausto, J. Jesús, "La colonización estanciera en la Nueva España" en Anuario Humanitas, Monterrey, Universidad Autónoma de Nuevo León, 1969, pp. 509-546.

Román Gutiérrez, José Francisco, Sociedad y evangelización en Nueva Galicia en el siglo ХИ, Zapopan Jal., El Colegio de Jalisco/Universidad Autónoma de Zacatecas, 1993.

Romero Frizzi, María de los Ángeles, "La agricultura en la época colonial", en Teresa Rojas (coord.) La agricultura en tierras mexicanas desde sus origenes hasta nuestros días, México, Consejo Nacional para la Cultura y las Artes/ Grijalbo, 1991, pp. 139-215.

Rubio Mañé, Ignacio, "Títulos de las villas de San Miguel el Grande y San Felipe", en Boletín del Archivo General de la Nación, t. II, núm. 3, julioseptiembre de 1961, 335-353.

Ruiz Guadalajara, Juan Carlos, Dolores antes de la independencia, Zamora, El Colegio de Michoacán, 2004.

Santacruz, Iris y Luis Gimenez-Cacho García, "Las pesas y medidas en la agricultura", en Siete ensayos sobre la hacienda mexicana 1789-1880, México, Instituto Nacional de Antropología e Historia, 1997, pp. 247- 264.

Santa María, fray Guillermo de, Guerra de los Chichimecas (México 1575 - Zirosto 1580), edición crítica, introducción, paleografía y notas de Alberto Carrillo Cázares, México, El Colegio de Michoacán/Universidad de Guadalajara/El Colegio de San Luis, 2003.

Servín, Enrique, El Camino Real de Tierra Adentro, México, Grupo Cementos de Chihuahua/Ceiba Arte Editorial, 2011.

Wright, David, La conquista del Bajio y los orígenes de San Miguel de Allende, México, Fondo de Cultura Económica, 1999. 